\title{
Determination of Pavement Elevations by the 3D Scanning System and Its Verification
}

\author{
Tomáš Křemen, Martin Štroner, Pavel Třasák \\ Czech Technical University in Prague, Faculty of Civil Engineering, Thákurova 7, 166 29, \\ Praha 6, Czech Republic, tomas.kremen@fsv.cvut.cz martin.stroner@fsv.cvut.cz \\ pavel.trasak@fsv.cvut.cz
}

\begin{abstract}
It is necessary to be careful of geometric accuracy of the roadways when constructing them. Correct thickness of the individual construction layers together with roughness of the pavement belongs among important influences ensuring lifetime of the roadways and vehicles and for comfortable and safe car ride. It is necessary beside other things to have a reliable check measurement method at disposal so as to ensure the required accuracy of the individual construction layers will be achieved. The check measurement method must be able to measure a checked construction component with the required accuracy and with sufficiently high density describing not only global deviations, but also local deviations.

The highest requirements on accuracy are placed on the final construction layer of the roadway. Layer thickness and pavement roughness are being evaluated here. The 3D terrestrial scanning method is currently offered for geometric checking of its realization. The article deals with testing of procedure of the pavement roughness measurement with the $3 D$ terrestrial scanning system and with its verification by a total station measurement. Emphasis is put on verification of accuracy of absolute heights of points in the $3 D$ model of the pavement and on size of random errors in the elevation component. Results of the testing clarified using the $3 D$ terrestrial scanning systems and their accuracy for check of the roadway surface.
\end{abstract}

Key words: 3D scanning, checking measurement, pavement roughness, elevation

\section{Introduction}

Several survey methods can be used for determination of pavement roughness. They are firstly these methods: precise geometric levelling with level instrument, trigonometric levelling by spatial polar method with total station, 3D scanning methods [1], [2] or photogrammetric method. Each of them has characteristic advantages and disadvantages that are important for choosing suitable method for specific job order. Accuracy, measurement density, time and labour consumption belong to these characteristics.

3D scanning methods - static and kinematics - are convenient because of measurement density, time and labour consumption [3], but examination of their accuracy suitability is complicated. Accuracy of kinematics methods is stated in centimetres [4]. This accuracy is usually suitable only for rough measurement. Accuracy of statics methods is stated in millimetres and it is enough for fine measurement.

Department of Special geodesy of the Czech Technical University in Prague was asked by the Control System International (CSI) Company to verify accuracy of the static terrestrial 3D scanning that was used for determination of the road pavement roughness.

The aim of the project was design and realization of checking procedure for verification of the scanning method. It was decided to build temporary test field in the area where standard 
commercial measurement was carried out. The precise trigonometric measurement with a total station was used for determination of spatial parameters of the test field. The field was measured by the CSI Company 3D scanning method. For comparison, the field was measured by the 3D scanning method of the Department of Special geodesy as well.

\section{Locality, survey net}

The measurements were carried out in the locality of Jinočanská spojka - Chaby in south-west part of Prague. There is four-lane highway with one bridge above the Dalejský brook. Road length is about $1.2 \mathrm{~km}$. The total length of the measured area was $2.5 \mathrm{~km}$ (measurement was carried out in both directions of the road). Test field was only in $150 \mathrm{~m}$ long part (Figure 1).

The surveying net was created for needs of the communication building. The surveying net was traverse consisting of six survey points located in the axis of the communication. The coordinates of the points were given by the investor. Accuracy of the survey net was checked and then improved for needs of the measurement verification.

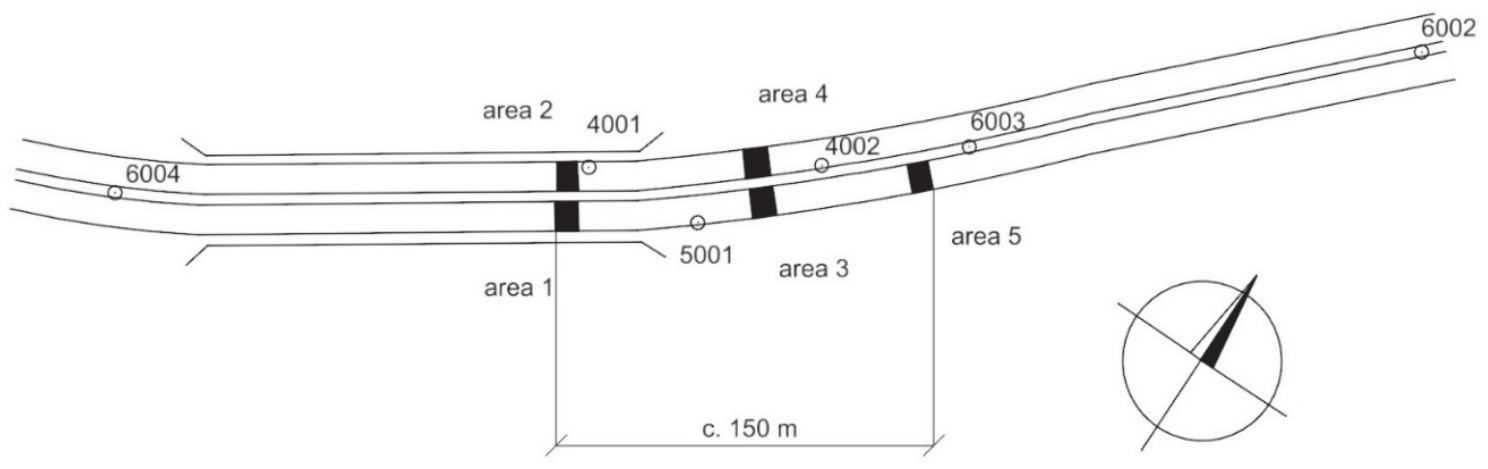

Figure 1: Position of the test field

\section{Instruments}

The rover Trimble 5800 (accuracy $10 \mathrm{~mm} 1 \mathrm{ppm}$ ), the Leica TCRA 1103 total station (accuracy of angle measurement is 1 mgon and accuracy of distance measurement is $2 \mathrm{~mm}+2 \mathrm{ppm} * \mathrm{D}$ ) and the Riegl VZ-400 3D scanning system was used for measurement by the CSI Company. The technical specification of the VZ-400 are: standard deviation of distance measurement in the range $100 \mathrm{~m}$ is $5 \mathrm{~mm}$, divergence of laser beam is $0.35 \mathrm{mrad}$, measurement range is up to $160 \mathrm{~m}$ for natural targets with more than $20 \%$ albedo and angle measurement resolution is better than $0,0005^{\circ}$ in both direction.

The total station Trimble S6 HP robotic (accuracy of angle measurement is 0.3 mgon and accuracy of distance measurement is $1 \mathrm{~mm}+1 \mathrm{ppm} * \mathrm{D}$ ) and 3D scanning system Leica HDS3000 was used for measurement by the department of Special geodesy. The technical specifications of the HDS3000 are: standard deviation of distance measurement is $4 \mathrm{~mm}$ up to $50 \mathrm{~m}$, spot size is $4 \mathrm{~mm}$ up to $50 \mathrm{~m}$, measurement range is up to $134 \mathrm{~m}$ for natural targets with more than $18 \%$ albedo and angle accuracy in both directions is $60 \mu \mathrm{rad}$.

\section{Measurement}

The measurements of the test field and the surface pavement of the road by VZ-400 were carried out in $24^{\text {th }}$ September 2013. The weather conditions were overcast and temperature about $12{ }^{\circ} \mathrm{C}$. The measurement of the test field by HDS3000 was carried out in $26^{\text {th }}$ September 2013. The 
weather conditions were overcast during measurement first four areas of the test field and during measurement of the last areas was sunshine. Temperature was about $12{ }^{\circ} \mathrm{C}$.

\subsection{Measurement of the test field}

The test field was designed as five separated areas. Each area was placed on a pavement surface. First two areas were placed on a bridge. The first area was in a two-lane part of the road inwards to the city. The second area was in a two-lane part of the road outwards direction from the city. Third and fourth areas were in the same places of the road as the previous two areas but about 85 $\mathrm{m}$ further in the direction to the city. The last fifth area was in a two-lane part of the road inwards to the city about $56 \mathrm{~m}$ further in the direction to the city than the third area (see Figure 1). Measurement of the test field was carried out by the precise trigonometric method with the Trimble S6 total station. Measurement was carried out from one position of the instrument (point no. 5001). The checking points were measured in one set (two positions of the telescope) for elimination of the instrument construction errors and higher accuracy. The measurement was carried out with automatic aiming at omnidirectional prism. Special flat peak on the bottom of the measuring rod was used. Three survey net points No. 6002, 6003 and 6004 were used for connection of the measurement into the state coordinate systems S-JTSK (position) and Bpv (elevation). Net of checking points with regular spacing among the points was measured in each area of the field. Numbers of checking points are shown in the Table 1.

Table 1: Number of checking points in the test field

\begin{tabular}{|l|c|c|c|c|c|c|}
\hline & $\begin{array}{c}\text { entire } \\
\text { field }\end{array}$ & 1. area & 2. area & 3. area & 4. area & 5. area \\
\hline number of points & 161 & 50 & 35 & 27 & 28 & 21 \\
\hline
\end{tabular}

\subsection{Measurement with VZ-400}

All parts of the communication were measured by 3D scanning technology owned by the CSI Company. This is its short description. The technology is founded on "stop and go" 3D scanning with georeferencing by GNSS and total station measurements. The scanner VZ-400 is mounted on the mast which is fixed to the car. The GNSS rover Trimble 5800 is mounted on the top of the scanner. Surrounding of the scanner is measured by the scanner and position of the scanner is measured by the GNSS rover. Area with radius $50 \mathrm{~m}$ is measured from one position of the scanning system. Density was bigger than 2000 points in $1 \mathrm{~m}^{2}$ on the ground (spacing $2 \mathrm{~cm} \times 2$ $\mathrm{cm})$. Next position of the system is usually $30-40 \mathrm{~m}$ further. Next measurement is carried out by total station. The control surfaces are measured along both sides of the road in regular spacing about $20 \mathrm{~m}$. These control surfaces are used for correction of the final 3D model elevation. Other detailed informations about measurement with this technology are business secret.

\subsection{Measurement with HDS3000}

Scanning with system HDS3000 is common static terrestrial measurement. The system HDS3000 was used only for measurement of test field areas. Each area of test field was scanned from one position of scanner. The density of scanning was set as $10 \mathrm{~mm}$ in horizontal and $5 \mathrm{~mm}$ in vertical direction of field of view in the distance $10 \mathrm{~m}$. It means that density of points in the pavement surface was bigger than $25 \mathrm{~mm}$ in longitudinal direction and $10 \mathrm{~mm}$ in transversal direction within the meaning of scanning direction. The range of measurement was from $3 \mathrm{~m}$ to $11 \mathrm{~m}$ in each area. Twelve control points were placed around the scanned areas. Four control points were placed around the first and the second area, next four control points were placed around the third and the fourth area and the last four control points were placed around the fifth area. The first four control points were measured by the Trimble S6 total station for connection into reference systems from 
the first free station (point 4001) and next eight points were measured by the same total station from the second free station (point 4002). The points 6003 and 6004 were used for connection of free stations to reference systems. Resection and detailed measurement were measured in one set.

\section{Processing}

\subsection{Determination of test field points coordinates}

The coordinates of test field points were firstly calculated in local coordinate system. Calculated heights were corrected from influence of Earth curvature $\Delta=\mathrm{d}^{2} / 2 \mathrm{R}$, where $d$ is horizontal distance and $R$ is Earth's radius. Then all points were transformed from local coordinated system into state reference systems. The points No. 6002, 6003 and 6004 were used for calculation of transformation key. The accuracy of the given elevations was low therefore it was made more precisely by the transformation. New elevations of the net's points were used for the next calculation. 161 checking points were determined. Accuracy of checking points' height is better than $1 \mathrm{~mm}$. This accuracy was determined from many previous measurements of displacements of bridges that were carried out by the Department of Special geodesy and from analysis of atmospheric refraction [5].

\subsection{Processing of VZ-400 measurement}

Measured data were transformed into the state reference systems by means of GNSS measurement and then they were adjusted by ICP algorithm in the "multi station adjustment" function in the RiSCAN Pro software. The measured data were reduced. Density of detailed points was 25 points $/ 1 \mathrm{~m}^{2}$ after reduction. Elevations of the detailed points were adjusted by means of control surfaces measured by the total station. Last operation was creation of locality digital terrain model (DTM). Elevation accuracy of this model was verified.

\subsection{Processing of HDS3000 measurement}

Measured data were transformed into the state reference systems. Control points measured by the total station were used. Elevations of the total station were corrected from influence of Earth curvature $\Delta$. Areas of test field were cut from the transformed point clouds. DTMs of areas were calculated. No other processing of point clouds was made.

\subsection{Verification of laser scanning technologies accuracy}

A special software for comparison of elevations of the test field checking points and elevations of DTMs from scanning in the same places was created for verification of laser scanning technologies. This software was created by our colleague Ing. Bronislav Koska, Ph.D. The software calculates high difference $\Delta h_{i}$ between elevation of checking point $h_{c p i}$ and elevation of DTM $h_{D T M i}$ in the same place:

$$
\Delta h_{i}=h_{c p i}-h_{D T M i} .
$$

High difference sample standard deviation $s_{\Delta h}$ is calculated for accuracy analysis:

$$
s_{\Delta h}=\sqrt{\frac{\sum_{1}^{n} \Delta h_{i}^{2}}{n-1},}
$$


where $n$ is number of high differences. The $s_{\Delta h}$ describes trueness and precision of the measurement with 3D scanning system. Trueness $t$ of the measurement is calculated as arithmetic mean of $\Delta h_{i}$ :

$$
t=\frac{\sum_{1}^{n} \Delta h_{i}}{n} .
$$

The precision $p$ of the measurement is calculated as sample standard deviation from high differences:

$$
p=\sqrt{\frac{\sum_{1}^{n} v_{i}^{2}}{n-1},}
$$

where $v_{i}$ is:

$$
v_{i}=t-\Delta h_{i} .
$$

The trueness gives us information about systematic error of 3D scanning transformation into the high reference system. The precision gives us information about high random errors of 3D scanning.

\section{Results}

The results of comparison of DTM elevation from 3D scanning and elevation of test field checking points are shown in the Table 2 . There are height difference sample standard deviation $s_{\triangle h}$, trueness $t$ and precision $p$ for whole test field and for particular areas of the field for used 3D scanning technology.

The results show that inner accuracy of the 3D scanning technology is around $1 \mathrm{~mm}$ and that HDS3000 is little better than VZ-400. Results of HDS3000 in $5^{\text {th }}$ area are worse than previous areas. It is probably caused by atmospheric refraction because sun came out from clouds during the measurement of this area. The entire accuracy of both 3D scanning is worse than accuracy in some particular areas. It is caused firstly by the systematic errors in transformation into the height reference system. Main part of the determined height differences for the 3D scanning with VZ400 is caused by wrong transformation into the height reference system.

Table 2: Results

\begin{tabular}{|c|c|c|c|c|c|c|c|}
\hline \multicolumn{2}{|c|}{ all values are in mm } & entire field & 1. area & 2. area & 3. area & 4. area & 5. area \\
\hline \multirow{3}{*}{ HDS3000 } & $s_{\Delta h}$ & 1.57 & 0.72 & 1.26 & 1.08 & 1.45 & 3.39 \\
\cline { 2 - 8 } & $t$ & 0.52 & 0.15 & -0.21 & -0.53 & 1.24 & 2.95 \\
\cline { 2 - 8 } & $p$ & 1.48 & 0.71 & 1.24 & 0.94 & 0.72 & 1.54 \\
\hline \multirow{3}{*}{ VZ-400 } & $s_{\Delta h}$ & 4.04 & 4.40 & 5.03 & 1.36 & 2.09 & 5.63 \\
\cline { 2 - 8 } & $t$ & 3.55 & 4.23 & 4.79 & 1.00 & 1.89 & 5.37 \\
\cline { 2 - 8 } & $p$ & 1.90 & 1.07 & 1.29 & 0.89 & 0.81 & 1.19 \\
\hline
\end{tabular}




\section{Conclusion}

The verification of static 3D scanning accuracy showed that both checked static 3D scanning methods are sufficient for works where demanding standard deviation in elevation is $5 \mathrm{~mm}$. The inner accuracy of 3D scanning is better than $2 \mathrm{~mm}$ but general error is influenced by errors in transformation into height reference system. Total station measurers' carefulness and calculation with all reduction especially with correction from influence of Earth curvature are very important because this correction can be up to several millimetres. Another source of the errors could be atmospheric refraction.

\section{Acknowledgements}

The article was written with support of the internal grant of Czech Technical University in Prague SGS14 "Optimization of acquisition and processing of $3 D$ data for purpose of engineering surveying “.

\section{References}

[1] KŘEMEN, T. - KAŠPAR, M. - POSPÍŠIL, J.: Operating Quality Control of Ground Machines by Means of the Terrestrial Laser Scanning System. In: Image Engineering and Vision Metrology [CD]. Dresden: ISPRS, 2006, ISSN 1682-1750.

[2] KŘEMEN, T. - POSPÍŠIL, J. - KOSKA, B.: Laser Scanning for Checking Earth Moving Works. In: INGEO 2008 - 4th International Conference on Engineering Surveying [CDROM]. Bratislava: Department of Surveying, SUT in Bratislava, 2008, ISBN 978-80-2272971-0, s. 1-10.

[3] ŠTRONER, M. - POSPÍŠIL, J. - KOSKA, B. - KŘEMEN, T. - URBAN, R. - SMÍTKA V. - TŘASÁK P.: 3D skenovací systémy. Praha, Česká technika - nakladatelství ČVUT, 2013, ISBN 978-80-01-05371-3.

[4] KOSKA, B.: Calibration of profile laser scanner with conical shape modification for autonomous mapping system. In: Proceedings of SPIE - Videometric, Range Imaging, and Applications XII; and Automated Visual Inspection, Munich, 2013, ISBN 978-0-81949607-2.

[5] URBAN, R. - MICHAL, O.: Analýza technologie pro určování průhybové čáry mostních konstrukcí. Grant Journal [online]. 2013, roč. 2, č. 2, ISSN 1805-062X. 